SANTOS, S.F. et al. Ocorrência de melanoma em equinos abatidos em matadouro frigorífico exportador de Minas Gerais. PUBVET, Londrina, V. 6, N. 1, Ed. 188, Art. 1268, 2012.

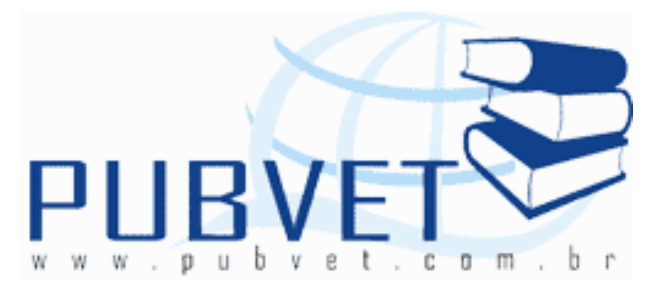

PUBVET, Publicações em Medicina Veterinária e Zootecnia.

\title{
Ocorrência de melanoma em equinos abatidos em matadouro frigorífico exportador de Minas Gerais
}

Silvia Ferreira dos Santos ${ }^{1 *}$, Mariana Assunção de Souza ${ }^{1}$, Raquel Peres de Oliveira $^{1}$, Ludimila de Souza ${ }^{2}$, Ana Carolina Portella Silveira ${ }^{3}$

${ }^{1}$ Mestranda em Ciências Veterinárias pela Faculdade de Medicina Veterinária, Universidade Federal de Uberlândia. Uberlândia, MG.

${ }^{2}$ Graduanda em Medicina Veterinária na Universidade Federal de Uberlândia ${ }^{3}$ Doutoranda do Instituto de Genética e Bioquímica da Universidade Federal de Uberlândia. Uberlândia, MG.

*Autor para correspondência: Rua Ceará, s/n, Bloco 2D, sala 43, CEP 38405303, Uberlândia, MG, Brasil. E-mail: raquelperes_o@yahoo.com.br

\section{Resumo}

Este trabalho teve por objetivo identificar a prevalência de melanoma em equinos abatidos em matadouro-frigorífico do Estado de Minas Gerais no período de 2004 a 2008 e o destino dessas carcaças inspecionadas durante exame sanitário post-mortem, baseando-se no diagnóstico macroscópico das lesões observadas, haja vista que neste frigorífico abateram-se animais de diferentes idades, cores, raças e procedências. Para a pesquisa de melanoma em carcaças o SIF faz observação do dianteiro da carcaça após a técnica do "despaletamento", mediante a abertura da musculatura da paleta, onde detecta lesão localizada quando se limita a área da paleta, lesões 
SANTOS, S.F. et al. Ocorrência de melanoma em equinos abatidos em matadouro frigorífico exportador de Minas Gerais. PUBVET, Londrina, V. 6, N. 1, Ed. 188, Art. 1268, 2012.

generalizadas se devem a disseminação de tumores ao longo da carcaça. E por meio dos resultados das constatações executados pela equipe da inspeção é que se tem a oportunidade de firmar-se um diagnóstico e um julgamento de caso por caso e dar-se logo o destino às carnes. E no período analisado (2004 a 2008) foram abatidos 137.769 equinos, sendo registrados 1.838 acometidos pelo melanoma, com prevalência de $1,33 \%$. Foi feito qui-quadrado e houve diferença estatística significativa entre os anos. Dos animais acometidos, $39,17 \%$ foram destinados a graxaria e $60,82 \%$ ao aproveitamento condicional.

Palavras-chave: carcaças, inspeção, matadouro- frigorífico, tumor maligno

\title{
Ocurrence of melanoma in horses butchered in slaughterhouse in Minas Gerais
}

\begin{abstract}
The aim of this study was to identify the prevalence of melanoma in horses butchered in slaughterhouse in Minas Gerais State from 2004 to 2008. It was also evaluated the fate of these carcasses based on the macroscopic injuries due the fact that the animals in this slaughterhouse are all of ages, colors races and origins. For the carcasses melanoma detection SIF perceives the front housing after the "despaletament" technique, opening the shoulder muscles, which detects localized damage when is limited to area of the shoulder, generalized injuries are due to spread of tumors throughout the carcass. The results of observations performed by the inspection team can provide the opportunity to sign up a diagnosis and a trial of case by case to give the destination once the meat. In the analysis period (2004 to 2008) were slaughtered 137,769 horses, 1,838 being recorded by melanoma affected, with prevalence of $1.33 \%$. Been done Chi - square and there was significant statistically difference among the years. $39.173 \%$ affected animals were left to grease and $60.82 \%$ conditional use.
\end{abstract}

Keywords: Analysis, physical-chemical, microbiological, milk, pasteurization 
SANTOS, S.F. et al. Ocorrência de melanoma em equinos abatidos em matadouro frigorífico exportador de Minas Gerais. PUBVET, Londrina, V. 6, N. 1, Ed. 188, Art. 1268, 2012.

\section{Introdução}

Melanoma são neoplasmas cutâneos que compõem de $4 \%$ a $15 \%$ dos tumores de pele de equinos. Mais de $90 \%$ dos tumores são inicialmente benignos e cerca de dois terços tornam-se malignos. (JOHNSON, 1998; SMITH; GOLDSCHMIDT; MCMANUS, 2002). O levantamento do número de equinos no Brasil pelo IBGE atinge seis milhões de animais sendo que destes 3 a 8\% são acometidos de melanoma (SILVEIRA, 2007).

Os melanomas estão diretamente relacionados com coloração, raça e idade dos animais, são freqüentes em animais velhos, de pelagem tordilha. Alguns autores chegam a afirmar que $80 \%$ dos eqüinos com pelagem branca, com idade acima de 15 anos, desenvolverão tumores melanocíticos (BONESI; BRACARENSE; MINELLI, 1998).

É um tipo de câncer proveniente dos melanócitos e o seu estabelecimento envolve diversas etapas, até a formação de um tumor invasivo e metatástico. O melanoma é um dos tipos de câncer de pior prognóstico e com alta incidência de metástases. (MANZAN et al., 2005). Melanócitos são células dendríticas ocorrentes na epiderme, que sintetizam melanina. A formação de grânulos de pigmento envolve a diferenciação dos melanoblastos em melanócitos (OUTINEN, 2002).

A melanina é produzida por uma via dependente da tirosina; assim, os melanócitos sintetizam a tirosinase e acumulam pigmento em organelas citoplasmáticas especializadas, chamadas melanossomas. A cor da pele é dada pela transferência desses melanossomas, dos melanócitos até os queratinócitos. Assim, são estas células, contendo pigmento que absorvem e dispersam a energia prejudicial proveniente da radiação ultravioleta. (JONES, 2000).

Os melanomas ocorrem com frequência variável na maioria das espécies animais. Nos cavalos tordilhos, estes tumores são processos neoplásicos que resultam de alterações nos melanócitos ou melanoblastos, que geralmente se apresentam como massas únicas ou múltiplas localizadas no tecido dermoepidermal ou subcutâneo. Cavalos tordilhos nascem com a pelagem escura. 
SANTOS, S.F. et al. Ocorrência de melanoma em equinos abatidos em matadouro frigorífico exportador de Minas Gerais. PUBVET, Londrina, V. 6, N. 1, Ed. 188, Art. 1268, 2012.

Inicialmente a pele permanece cinza escuro, com exceção de manchas semelhantes a vitiligo; com a idade o pêlo torna se progressivamente branco, esta despigmentação se inicia ao redor dos olhos e na região anal, o que contribui para a ocorrência de melanomas nestas áreas (CAMPOS, 2007).

Nas raças brancas, geralmente os corpos celulares dos melanócitos estão restritos às camadas basais da epiderme, entretanto, seus prolongamentos dendríticos estendem se entre as células da epiderme. Geralmente, na derme há poucas células contendo melanina. Já a formação de melanina antes do nascimento pode ser observada na epiderme das raças de pele escura, a produção desta começa antes do nascimento e distribuem pelas células da epiderme. Um aumento da produção ocorre em resposta à luz ultravioleta, sendo que o teor relativo do pigmento nos melanócitos é o responsável pelas diferentes cores da pele (MOORE; PERSAUD, 2000).

O melanoma é comumente identificado macroscopicamente por sua cor intensamente negra e pelo pigmento escuro que pode difundir-se para qualquer meio aquoso com o qual a superfície de corte entre em contato (JONES, 2000).

São comuns as formações nodulares nos melanomas podendo disseminar-se localmente e desenvolver-se em órgãos internos, o que é sugestivo de metástase (BONESI; BRACARENSE; MINELLI, 1998). As formas malignas são geralmente muito agressivas com rápida disseminação generalizada nos principais órgãos e cavidades corpóreas (KNOTTENBELT, 2003).

Os tumores melanocíticos ocorrem em tantas formas e locais, que se torna difícil fazer qualquer generalização. Melanomas quiescentes ou ativamente malignos são especialmente frequentes em cavalos tordilhos idosos, embora esses tumores também ocorram em cavalos de outras cores. Essas neoplasias são particularmente comuns nas regiões perianais e perirretais e outros nodos linfáticos pélvicos. Em alguns casos equinos, a morte resulta da metástase ao baço, pulmões, ou outros órgãos internos, sem que a lesão primária tenha sido encontrada (JONES, 2000). 
SANTOS, S.F. et al. Ocorrência de melanoma em equinos abatidos em matadouro frigorífico exportador de Minas Gerais. PUBVET, Londrina, V. 6, N. 1, Ed. 188, Art. 1268, 2012.

A maioria dos tumores melanocíticos inicia-se na região ventral da cauda, no períneo e na genitália externa e, menos comumente, na glândula parótida, na orelha, na pálpebra, nos membros e no pescoço. Após transformação maligna, a formação de metástases ocorre via hematogênica, linfática ou por implantação, e os principais locais envolvidos são linfonodos regionais, baço, fígado, pulmões, vasos sanguíneos e coração (FLEURY et al., 2000; JOHNSON, 1998; MACGILLIVRAY; SWEENEY; PIERO, 2002).

O melanoma tem uma grande importância patológica, pois o mesmo apresenta dificuldades quanto a deteç̧ão no processo inicial e ainda que detectado implica num prognóstico desfavorável quanto ao tratamento e cura. As lesões tumorais em equinos são tipicamente localizadas na derme, podendo disseminar metástases e provocar disfunções em órgãos, causando até a morte (BONESI; BRACARENSE; MINELLI, 1998).

Apesar de os tumores melânicos em equinos desenvolverem-se na região do períneo e na base da cauda, inúmeros órgãos e tecidos, como o muscular e o ósseo, são atingidos (BONESI; BRACARENSE; MINELLI, 1998).

Este trabalho teve por objetivo identificar a prevalência de melanomas em equinos abatidos em matadouro-frigorífico do Estado de Minas Gerais no período de 2004 a 2008 e o destino dessas carcaças inspecionadas durante exame sanitário post-mortem.

\section{Material e métodos}

A pesquisa foi desenvolvida durante os anos de 2004 a 2008 no Município de Araguari, Minas Gerais, em estabelecimento exportador de carnes equina para o Japão e países da União Européia. Para o estudo, foram analisados os dados fornecidos pelo Serviço de Inspeção Federal, cujo diagnóstico pós - mortem foi baseado no aspecto macroscópico das lesões observadas, dos animais de diferentes idades, raças e procedências, cores abatidos pelo frigorífico.

Para a pesquisa de melanoma em carcaças, o SIF faz observação do dianteiro da carcaça após a técnica do "despaletamento", mediante a abertura 
SANTOS, S.F. et al. Ocorrência de melanoma em equinos abatidos em matadouro frigorífico exportador de Minas Gerais. PUBVET, Londrina, V. 6, N. 1, Ed. 188, Art. 1268, 2012.

da musculatura da paleta onde detecta lesão localizada quando se limita a área da paleta. As lesões generalizadas se devem a disseminação de tumores ao longo da carcaça.

Por meio dos resultados das constatações executados pela equipe da inspeção é que se tem a oportunidade de firmar-se um diagnóstico e um julgamento de caso por caso e dar-se logo o destino às carnes.

Os dados foram tabulados e analisados observando a ocorrência em um período de cinco anos (2004 a 2008). Foi feito um teste Qui-quadrado para verificar se havia diferença estatisticamente significativa entre as frequências encontradas para o melanoma nos anos pesquisados com um nível de significância de 0,1\% (SAS, 2001).

\section{Resultados e Discussão}

No período 2004 a 2008 foram abatidos 137769 equinos e registrados 1.838 animais acometidos pelo melanoma, com prevalência de 1,33\%. E analisando a frequência do tumor em equinos abatidos durante os cinco anos encontrou se diferença estatística significativa entre os anos conforme Tabela 1.

Bonesi e outros (1998) em estudo com equinos de pelagem clara e acima de cinco anos foram visto que, dos 2.982 eqüídeos estudados (100\%), observou-se melanomas em 2.105 animais (70,5\%), podemos constatar uma diferença entre as prevalências, pois encontramos neste trabalho 1,33\%.

Nos equinos de pelagem clara a proliferação tumoral e metástase são realizadas de uma forma bastante lenta, permitindo os animais conviverem mais tempo com a doença sem complicações mais sérias. Daí as maiores incidências em animais de pelagem clara e idosos. Já os animais de pelagem escura têm proliferação tumoral bastante acelerada, além de metástases e morrem relativamente cedo devido a proliferação tumoral, são menos acometidos (RIEDER et al, 2000). Quando se analisa apenas a pelagem clara a incidência é bem maior, já que os mesmos conseguem conviver com a doença por mais tempo em relação aos de pelagem escura que quando acometidos 
SANTOS, S.F. et al. Ocorrência de melanoma em equinos abatidos em matadouro frigorífico exportador de Minas Gerais. PUBVET, Londrina, V. 6, N. 1, Ed. 188, Art. 1268, 2012.

tem proliferação metatástica e morte mais precoce além de que são raramente afetados.

Pode-se destacar a elevada incidência de melanoma em indivíduos de pele clara expostos a radiação ultravioleta da luz solar, pois a radiação ionizante e os raios ultravioleta induzem transformação neoplásica em vários tecidos. A sensibilidade de células à radiação é bastante variável, em geral a sensibilidade à radiação ocorre em proporção direta de sua atividade mitótica e proliferativa e inversa a seu grau de diferenciação. A transferência de energia dos diferentes tipos de radiação para as moléculas e átomos das células pode ser bastante rápido (como apenas alguns segundos). Entretanto, seus efeitos biológicos, em especial oncogênico, podem levar anos para aparecer, devido à ação cumulativa e ao longo período de latência para aparecimento das neoplasias (MAJNO; JORIS, 1996; MONTENEGRO e FRANCO, 1999, JONES; HUNT ; KING, 2000).

Foi observado que a frequência de melanoma no período de 2006 a 2008 permaneceu constante, mas a baixa prevalência de 1,33\% sugere pouca quantidade de equinos pelagem clara abatidos pelo frigorífico, haja vista que neste estudo abateram-se animais de diferentes idades, cores, raças e procedências, em comparação aos trabalhos citados na literatura feitos apenas com animais de pelagem clara tiveram prevalências superiores, além de que a inspeção do frigorífico em estudo passou a exigir seleção na compra e refugando aqueles animais com melanomas aparentes. Embora seja notável que os fatores predisponentes como a coloração, idade, raça e a procedência dos mesmos estão envolvidas com a ocorrência de melanoma. 
SANTOS, S.F. et al. Ocorrência de melanoma em equinos abatidos em matadouro frigorífico exportador de Minas Gerais. PUBVET, Londrina, V. 6, N. 1, Ed. 188, Art. 1268, 2012.

Tabela 1. Ocorrência de melanomas em carcaças de equinos abatidos em matadouro-frigorífico, Araguari MG, 2004-2008

\begin{tabular}{cccc}
\hline ANO & ABATIDOS & ACOMETIDOS & \multicolumn{2}{c}{$\begin{array}{c}\text { FREQÜÊNCIA DE } \\
\text { MELANOMA EM } \\
\text { EQUINOS }(\%)\end{array}$} \\
\hline 2004 & 38359 & 925 & $2,41 \mathrm{a}$ \\
2005 & 42347 & 241 & $0,56 \mathrm{~b}$ \\
2006 & 24810 & 303 & $1,22 \mathrm{c}$ \\
2007 & 18565 & 223 & $1,20 \mathrm{c}$ \\
2008 & 13688 & 146 & $1,06 \mathrm{c}$ \\
\hline TOTAL & 137769 & 1838 & 1,33 \\
\hline
\end{tabular}

As letras diferentes na mesma coluna diferem entre si pelo teste do qui-quadrado ( $\mathrm{p}$ $<0,001)$.

As carcaças de equinos rejeitadas para exportação por estarem acometidas de melanoma têm os seguintes destinos: Lesões localizadas têm se o aproveitamento condicional, (salsicharia, embutidos, recortes). E quando há o acometimento generalizado das carcaças tem-se rejeição total e são destinadas a graxaria. (GUIMARÃES ; SANTOS, 2001).

De 2004 a 2008, 1838 animais foram acometidos, sendo que 39,17\% foram destinados a graxaria por conter lesões generalizadas e 60,82\% ao aproveitamento condicional (Tabela 2 ). As carcaças rejeitadas com lesões localizadas têm se o aproveitamento condicional, na qual atualmente tem destinado a salsicharia (fabricação de embutidos cozidos), visto que não se tem um mercado para consumo interno de carne eqüina. Lesões generalizadas têm se rejeição total e são direcionadas a graxaria.

\section{Conclusão}

Conclui-se que a frequência de melanoma em equinos no período de 2004 a 2008 foi de 1,33\%. Dos animais acometidos, 39,17\% foram destinados a graxaria e $60,82 \%$ ao aproveitamento condicional. 
SANTOS, S.F. et al. Ocorrência de melanoma em equinos abatidos em matadouro frigorífico exportador de Minas Gerais. PUBVET, Londrina, V. 6, N. 1, Ed. 188, Art. 1268, 2012.

Tabela 2. Distribuição da frequência de melanomas em carcaças de equídeos de abatidos em matadouro-frigorífico sob Inspeção Federal, segundo o destino das carcaças, Araguari MG, $2004-2008$

\begin{tabular}{cccc}
\hline ANOS & ACOMETIDO & GRAXARIA \% & $\begin{array}{c}\text { APROVEITAMENTO } \\
\text { CONDICIONAL \% }\end{array}$ \\
\hline 2004 & 925 & 29,40 & 70,59 \\
2005 & 241 & 56,01 & 43,98 \\
2006 & 303 & 40,92 & 49,92 \\
2007 & 223 & 44,39 & 55,60 \\
2008 & 146 & 61,64 & 38,35 \\
\hline Total & 1838 & 39,17 & 60,82 \\
\hline
\end{tabular}

\section{Referências}

BONESI, L. G.; BRACARENSE, L.R.P.A.; MINELLI, L.; Melanoma em equídeos de pelagem branca - frequência, distribuição e lesões em carcaças VOLUME 73 - No 6: Investigação clínica,epidemiológica, laboratorial e terapêutica. Anais bras Dermatol, Rio de Janeiro, 73(6):533-538, nov./dez.1998.

CAMPOS, S. S. G. A.; Melanoma equino: Relato de Caso. 2007. 35f. Monografia, Recife 2007.

FLEURY, C. BÉRARD, F.; LEBLOND, A.; FAURE, C.; GANEM, N.; THOMAS, L.; The study of cutaneous melanomas in Camargue-type gray-skinned horses (2): epidemiological survey. Pigment Cell, v.13, p.47-51, 2000.

GUIMARÃES J. A., SANTOS, J.C.; Inspeção sanitária e industrial dos produtos de origem animal (controle oficial - sanitário e tecnológico). Revista CFMV. Ano 7 - No 23 - p.6-11, 2001.

JOHNSON, P.J.; Dermatologic Tumors (excluding sarcoids). Veterinary Clinics of North Equine Practice, v.14. pg.643- 658, 1998.

JONES T. C.; HUNT R. D.; KING N. W. Patologia Veterinária $6^{\circ}$ ed. Editora Manole , 2000 p.871-873.

KNOTTENBELT .D. C.; Skin neoplasia: melanoma. 2003. Disponivel em: $\leq$ http://www.ivis.org/proceedings/SIVE/2003/lectures/knottenbelt4.pdf. $>$ Acesso em: 10 nov. 2008.

MACGILLIVRAY, C.K., SWEENEY W. R.; PIERO, D. F.; Metastatic melanoma in horses. Journal of Veterinary Internal Medicine, v.16, p.452- 456, 2002.

MAJNO, G.; JORIS, O.; Cells, tissues and disease. Principles of general Pathology. Blackwell Science, p. 973, 1996. 
MANZAN, M. R.; JUNIOR, S. R. A.; PERINELLI, C. S.; BERTONCELLI, F. D. M.; ZICA, P. V.; Considerações sobre Melanoma Maligno em cães: uma abordagem histológica. Boletim de Medicina Veterinária Vol.1, No 1, 2005.

MOORE, K. L.; PERSAUD, T. V. N. Embriologia Básica, $5^{\circ}$ ed. Editora Guanabara 2000 p. 115-118.

MONTEnegro, M.R.; FRANCO, M, M. Patologia. Processos Gerais, Atheneu, 4a edição, 1999 , p. 320.

OUTINEN.H.I.; NF1 supressores tumorais na pele: Manifestação em resposta ao trauma tecidual e na diferenciação celular. 2002.

Disponívelem: $\leq$ http://herkules.oulu.fi/isbn9514266463/html/x563.html. $>$ Acesso em: 07 de novembro de 2008

RIEDER S., STRICKER C., JOERG H., DUMMER R.; STRANZINGER G. A comparative genetic approach for the investigation of ageing grey horse melanoma. Journal of animal Breeding genetics .117. 73-82, 2000.

SMITH, S. H.;GOLDSCHMIDT, H. M.; MCMANUS, M.P.; A comparative review of melanocytic neoplasms. Veterinary Pathology, v.39, n.6, p.651-678, 2002.

SILVEIRA, E.; Oncocell Biotecnologia- Mercado de cavalos de raça é alvo de vacina contra câncer de pele desenvolvida a partir de produto similar já utilizado em ser humano, 2007. Disponível em: <http://www.inovacao.unicamp.br/pipe/report/070429-oncocell.shtml > Acesso em: 7 mai. 2008.

STATISTICAL ANALYSIS SYSTEM. SAS User's Guide. 8.1 ed. Cary: SAS Institute, 2000. 